\title{
SAÚDE E EDUCAÇÃO: PISTAS PARA UMA CLÍNICA DA DIFERENÇA
}

\author{
Leonardo Kozoroski Oliveira ${ }^{1}$ \\ Guilherme Carlos Corrêa
}

\begin{abstract}
Resumo: No presente trabalho iremos problematizar a saúde e a doença como dois pontos importantes da vida se entendidas como agentes mobilizadores do pensamento. Destacamos como uma ideia de oposição entre saúde e de doença pode ser fonte do adoecimento, se investida em padrões generalizados aplicáveis a qualquer situação. Para isso, este trabalho conta com três movimentos: o primeiro concentra-se em como é instituída em nosso pensamento uma noção de saúde como oposta a doença e que complicações as ações orientadas por tal noção podem gerar. O segundo movimento apresenta o funcionamento de uma noção de saúde que abra espaço às multiplicidades em favor das potências de vida. No terceiro movimento trazemos algumas pistas para um trabalho clínico-educacional que desloca a centralidade do diagnóstico na problematização de questões vivas, possível em equipes de trabalho e situações educacionais. Este texto procura investigar as potências de uma clínica voltada às multiplicidades, considerando a doença como oportunidade de aprendizado, abundância de vida e apoio mútuo.
\end{abstract}

Palavras-chave: saúde; clínica; educação

\section{SALUD Y EDUCACIÓN: PISTAS PARA UNA CLÍNICA DE LA DIFERENCIA}

Resumen: En el presente trabajo discutiremos la salud y la enfermedad como dos puntos importantes de la vida si se entienden como agentes que movilizan el pensamiento. Destacamos cómo una idea de oposición entre salud y enfermedad puede ser una fuente de enfermedad, si se invierte en estándares generalizados aplicables a cualquier situación. Para ello, este trabajo tiene tres movimientos: el primero se centra en cómo se instituye en nuestro pensamiento una noción de salud frente a enfermedad y qué complicaciones pueden generar las acciones guiadas por tal noción. El segundo movimiento presenta el funcionamiento de una noción de salud que da lugar a multiplicidades a favor de los poderes de la vida. En el tercer movimiento, aportamos algunas pistas sobre el trabajo clínico-educativo que cambia la centralidad del diagnóstico en la problematización de posibles cuestiones vitales, en equipos de trabajo y situaciones educativas. Este texto busca investigar el potencial de una clínica enfocada en multiplicidades considerando la enfermedad como una oportunidad para el aprendizaje, la abundancia de vida y el apoyo mutuo.

Palabras clave: Salud; clínica; educación

\footnotetext{
1 Bacharel em Psicologia (URI - Santiago) e Mestre em Educação (UFSM). E-mail: leonardopsic@gmail.com

${ }^{2}$ Licenciado em Química, Mestre em Educação e Ciências e Doutor em Ciências Sociais-Política. Docente do curso de Licenciatura em Química da Universidade Federal de Santa Maria. E-mail: guilherme.correa@ufsm.br
} 


\section{Introdução}

Nossa intenção, neste trabalho ${ }^{3}$ é produzir uma problematização das noções de saúde e doença como estados do vivido capazes de mobilizar o pensamento, ou seja, capazes de intensificar a vida. Destacamos como a composição saúde-doença, quando seus termos são tomados como opostos em padrões generalizados aplicáveis a qualquer situação, contribui para uma despotencialização do vivido e das relações entre as pessoas seja consigo mesmas, seja em composições grupais ou sociedades.

Para isso, este trabalho terá três movimentos: o primeiro concentra-se em como é instituído em nosso pensamento uma noção de saúde como oposta a doença e que complicações esta noção provoca quando generaliza-se na orientação de situações de vida. O segundo movimento, tem como interesse o funcionamento de uma noção de saúde que abra espaço à multiplicidade do pensamento e que encontre potências de vida na doença e não apenas uma ausência de saúde. Em um terceiro movimento vamos apresentar algumas pistas para o emprego de uma noção de saúde que desfoca o diagnóstico clínico tradicional como eixo central das práticas em saúde.

A principal referência deste artigo é o texto de Oswaldo Giacóia Junior intitulado 'Saúde, doença e ressentimento' (GIACÓIA, 2013). O leitor poderá estranhar não termos feito nenhuma citação ou qualquer outra referência a este trabalho. No entanto, é nele que encontramos uma compreensão da noção de saúde para Nietzsche e, mais que citar ou fazer referências a expressões ou partes do texto, preferimos operar com o conceito de saúde que muitas e variadas nuances são ali apresentadas.

\section{A oposição saúde-doença}

O conceito de uma saúde que se tornou majoritário na atualidade, foi se constituindo ao longo dos tempos, bastante atravessado por uma cultura de talhe científico com fortes marcas das ideias humanistas e positivistas. Tal conceito tem como base um princípio de verdade que se universaliza a partir de uma noção de saúde como oposta à doença. Segundo esse princípio, torna-se indispensável sair de

\footnotetext{
${ }^{3}$ Inspirado nos resultados da pesquisa de Mestrado em Educação de Oliveira (2017).
} 
Criar Educação, Criciúma, v. 9, ํㅡ 3, ago/dez. 2020 - PPGE - UNESC - ISSN 2317-2452

um sintoma o mais rápido possível, para que se estabeleça novamente a condição de saúde.

No mundo contemporâneo, existem, pelo menos, dois modos de propagação da noção da saúde vigente: a produção científica e a mídia (todas as modalidades de comunicação de massa). Tais âmbitos aparecem em favor da produção de modos de ser. Para isso, são ofertados tratamentos alinhados a estilos de vida e a concepções de normalidade para tratar corpo e mente.

Uma noção majoritária de saúde ganha, então, vigência. É a partir de diagnósticos que ela se justifica para disseminar modelos de tratamentos. Neste contexto, a indústria farmacêutica ganhou força: desde o tratamento para usuário de drogas, passando por crianças e adolescentes em escolas e clínicas particulares e para idosos em asilos. Nessas instituições, a indústria farmacológica impera pela via de prescrições, de prontuários, de receitas e de adequação do pensamento em saúde às necessidades de uma política de Estado e de mercado. Uma vez prescrito, por exemplo, um psicofármaco, o paciente toma a medicação como agente fundamental do seu tratamento, o qual, mais e mais, tende a estender-se por toda vida.

Assim, temos um aumento da medicalização e das formas coercitivas de tratamento como, por exemplo, a internação compulsória de usuários de drogas, em que uma das consequências disso é a redução dos processos de autonomia, impedindo o paciente da saúde mental a ter mais independência e compreensão de seus processos de saúde. "Certo ou errado, a psiquiatria e a psicologia já entraram na vida cotidiana dos homens. Quebram os limites da especialização e influenciaram nas relações sociais, na cultura, nos costumes" (BERLINGUER, 1973, p. 01).

O pensamento e o desejo tiveram, no ocidente, uma elaboração precedente da relação saúde/doença. Encontramos nos gregos, como Platão e Aristóteles, formulações que inauguraram aspectos daquilo que pensamos e desejamos.

Nesse sentido, para Platão, pensar jamais significa produzir ou inventar uma realidade nova, pois o valor de verdade só pode ser atribuído a um conhecimento que imite ou reproduza - por semelhança - as relações internas do modelo inteligível e imutável (FUGANTI, 2008, p. 26).

Neste modelo pode até existir aquilo que chamam de novo: uma nova educação e uma nova saúde. Porém, no quadro referencial platônico não podem 
ultrapassar as obrigações e os modelos, uma vez que estão forçadas a reproduzir e afirmar estes mesmos modelos. Ou seja, o novo como adequação e aperfeiçoamento de um modelo ideal funciona como uma espécie de coerção do pensamento e, portanto, da própria novidade.

Uma separação do pensamento e da vida é o que Platão está operando na esteira de Sócrates. Ele está construindo uma máquina de pensar fundada no negativo e reduzindo o pensamento à razão e ao reconhecimento; ele denuncia os corpos indóceis como obstáculo à razão e à virtude, reduzindo a vida à vida reativa (FUGANTI, 2008, p. 28).

A verdade, a partir da visão socrática, foi apropriada por religiões, pelos estados em suas constituições e anima muitos âmbitos da experiência humana, tais como a ciência, a tecnologia, a informação e as instituições. Desse modo, a verdade fundada em ideais (de homem, de instituições e, ainda, de objetivos e meios que conduziriam a situações ideais) tem como efeito prático a produção de processos cujo principal mobilizador, tanto analítico quanto crítico, é a falta. Frente a um modelo ideal qualquer coisa, situação ou processo está em falta.

Comparados aos ideais estamos sempre em falta. Em constante regime de falta, produzimos nossas vidas e, nelas, a naturalização de oposições - bem-mal; certo-errado; bonito-feio; real-irreal e assim por diante. Fuganti (2008), referindo-se ao desejo e ao pensamento, apresenta que Platão:

[...] os dirige para as alturas das formas puras; funda uma crença, a crença nas essências inteligíveis como valores supremos que existem separadas dos corpos sensíveis, e opera uma hierarquia de sentidos apreendidos ao mesmo tempo como causas da ordem universal e paradigmas da existência humana (FUGANTI, 2008, p. 29).

A falta em relação às formas puras ideais foi o efeito que se obteve da apropriação e do grande investimento em que, historicamente, empenham-se as instituições que conformaram religiões e Estados. Nosso modo de pensar, nossas instituições, nossos desejos e nossas recusas são, na medida em que nascemos e crescemos dentro dessas instituições, marcados pela falta.

É nesse sentido que se pode falar dessas instituições como agências de universalização da falta pela via da moralização decorrente da preponderância de ideais e seus correspondentes opostos. É daí, portanto, que se pode falar de uma 


\section{CRIAR EDUCAÇÃO}

Revista do Programa de Pós-Graduação em Educação - UNESC

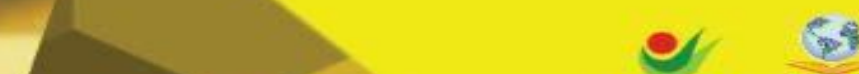 \\ unesc PPGE

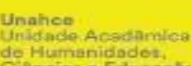 \\ Ciancias o Educass \\ ediunesc}

Criar Educação, Criciúma, v. 9, oㅜ 3, ago/dez. 2020 - PPGE - UNESC - ISSN 2317-2452

saúde universal, ou seja, de instituições voltadas a realizar as operações que se julgam necessárias para nos aproximar e nos comparar constantemente a um ideal de homem, com sua saúde ideal.

Assim, o pensamento, no prisma platônico, não pode ter uma evolução num sentido de desvio, de invenção. Ao contrário, ele deve se adequar a um só sentido, aquele dito e fundado como valorativo a uma só linha, mas não qualquer linha, a linha de definições preestabelecidas que se adequam a valores. Em Platão, conforme afirma Fuganti (2008)

[...] doenças são frutos dos vícios e da escravidão do homem às suas paixões inferiores. Um corpo saudável, equilibrado e harmonioso é aquele que obedece às ordens dietéticas ditadas pela alma racional, é um corpo comedido (p. 27-28).

No contemporâneo, se deslocarmos essa questão para o contexto de uma doença, veremos surgir noções idealizadas e preestabelecidas de tratamento, comportamento e saúde. Logo, tudo que está aquém ou além dessas concepções torna-se desvio e deve ser ajustado.

No momento em que a saúde pode ser pensada em termos de bem-estar (físico, psíquico ou social), este passa a ser considerado como valor. [...] E, assim, será pensado como contravalor, como seu reverso patológico e passível de assistência, tudo aquilo que possa ser considerado perigoso ou não desejado (CAPONI, 2000, p. 17).

Perigoso ou não desejado seria, então, tudo aquilo que desvia da figura difusa, imaterial e não realizável do homem ideal (sua conduta em sociedade, seu desenvolvimento físico/intelectual, sua adequação às instituições e as leis).

Aqueles cuja situação de saúde se afaste, de maneira observável, da considerada normal - e normal é um dos maiores e mais importantes abrigos do ideal - devem ser reconduzidos a estados normais de saúde. O estado doentio percebido como desvio em relação ao ideal faz com que se queira um restabelecimento da saúde. É esse modo de pensar que guia as práticas de saúde majoritárias tornadas universais, as quais acabam desqualificando, encobrindo, deslegitimando práticas menores.

As práticas majoritárias são conectadas a modos majoritários de pensar e modos majoritários de pensar pretendem unanimidade. Não seria a tendência à 


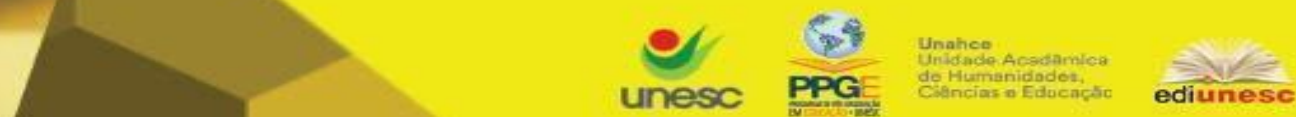

Criar Educação, Criciúma, v. 9, oㅜ 3, ago/dez. 2020 - PPGE - UNESC - ISSN 2317-2452

unanimidade promovida pelo pensamento majoritário em saúde o que dá coerência a afirmações de que a depressão é doença, que o drogado é doente e que o álcool leva a outras drogas? A saúde, enfim, tem sido tomada como oposto de doença, pautada pela falta, pelo diagnóstico unilateral, pelo tratamento como recuperação da saúde (ideal) perdida e pela inovação condenada a repetir e afirmar ideais.

O trabalho a se pensar não é, todavia, o de opor-se ao pensamento platônico, mas afirmar a solução platônica como múltipla uma vez que liberada da sua prisão dual. Ser percebido e auto perceber-se pela falta torna a vida muito dura, cansativa e chata. Somos, contudo, iniciados e constantemente mantidos neste exercício em que nos dispomos a ser julgados, medidos, avaliados, tratados, punidos, adequados a partir de um insuperável estado de falta.

Estado de falta cuja suposta superação toma todas as nossas forças e acaba por dar sentido ao que teimamos ou insistimos em chamar de vida. Que vida é possível quando tudo o que fazemos, pensamos e desejamos está comprometido com o gesso da cura, do alívio e do consolo utilizados para nossa aproximação ao ideal e cujo o efeito é invariavelmente imobilidade?

É o caso dos usuários de drogas, por exemplo, que:

[...] vitimizados pela captura-dependência que as substâncias químicas ilícitas Ihes provocariam, de tal maneira que eles deixaram de ser sujeitos desejantes para serem meros objetos inertes e irresponsáveis quanto aos seus próprios atos (MERHY, 2012, p. 09).

E, na esteira dos processos possíveis entre doença e ideal de saúde, o autor acrescenta:

Esse processo atual tem mobilizado muitos recursos por parte de variados setores sociais, como expressão das conquistas que o pensamento conservador e reacionário tem produzido, inclusive com o apoio de uma ampla rede multilinguística de produção comunicativa, que utiliza dos mais variados veículos de comunicação de massa imagéticas, orais, textuais. Além disso, conseguiram se aliar a um certo agrupamento social que advoga para si as formulações tidas como "científicas" e, portanto, produtoras das verdades sobre o problema que eles mesmo nomeiam, como as expressas por certas entidades corporativas do campo da saúde, como: conselhos profissionais, sociedades de especialidades, e mesmo por figuras populares que atravessam todos esses lugares, como os médicos midiáticos, por exemplo (MERHY, 2012, p. 09). 
É no sentido de encarar os processos tornados doentios como oportunidade de aprendizagens únicas e tomadas como movimentos de vida, e não de imobilização pautada por ideais que aprisionam a maneira de pensar, sentir e desejar que inaugurase uma perspectiva de saúde em que o estado doentio deixa de ser sinônimo de oposição ou diminuição da vida. Um movimento, então, que desperta a saúde a partir do encontro com situações que antes eram percebidas como contrárias à vida: uso de drogas, depressão, ansiedade, comprometimento da mobilidade corporal, da capacidade de expressão, etc.

É o caso daqueles cujo o sofrimento constitui abundância de vida, excesso e poder de redirecionamento das forças. Principalmente as forças que seriam gastas ou dispersas pelo ressentir constante e pelo mastigar cansativo das memórias tristes. Diferentemente disso, com Nietzsche, temos aí uma valiosa pista que consistiria, basicamente, em esquecer ou fragilizar o ressentimento por uma espécie de povoamento do horizonte. Horizonte em que o ressentimento, por meio de nossa tendência natural à doença - ou ao ressentimento - toma conta da paisagem.

\footnotetext{
Mas existem dois tipos de sofredores: os que sofrem de abundância de vida, que querem uma arte dionisíaca e também uma visão e compreensão trágica da vida, e depois os que sofrem de empobrecimento de vida, que buscam silêncio, quietude, mar liso, redenção de si mediante a arte e o conhecimento, ou a embriaguez, o entorpecimento, a convulsão, a loucura (NIETZSCHE, 2001, p. 272).
}

Para aqueles que a doença é questão de excesso, de proliferação de perspectivas e de inquietação, "saúde e doença não são essencialmente diferentes" (NIETZSCHE, 1888, p. 250). Todavia, para estes, os estados doentios, de debilidade e fraqueza são, ao mesmo tempo, oportunidade tanto para entronizar o ressentimento ou a ele sucumbir quanto para percebê-lo como algo entre outras tantas coisas. Se Nietzsche refere-se ao ressentimento a partir da percepção da arte, nossa intenção é dar destaque à pouca importância da dualidade saúde/doença e um investimento no poder de trânsito do estado doentio como estado mesmo de saúde, na medida em que a doença pode ser tomada como estado de transvaloração do pensamento e da vida. 


\section{r o \\ unesc PPGE

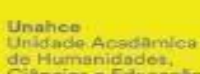 ediunesc}

Criar Educação, Criciúma, v. 9, ํㅜ 3, ago/dez. 2020 - PPGE - UNESC - ISSN 2317-2452

Porém, suportar o estado doentio sem recorrer a nenhum tipo de entorpecente ou subterfúgio é uma dimensão fundamental do além do homem. Mas como é possível superar toda essa impotência? Pensar a partir de estados de fraqueza quando somos acometidos por uma doença requer uma transvaloração da doença. Trata-se de desconstruir aquilo a que a doença nos remete como sendo dor-limitação em favor de uma dor-movimento.

Uma estrutura social e política destruidora apresenta como álibi o poder de encher suas vítimas com terapias que elas foram ensinadas a desejar. 0 consumidor de cuidados da medicina torna-se impotente para curar-se ou curar seus semelhantes (ILLICH, 1975, p. 06).

É possível que os estados doentios possam servir como um passo para a saúde? Sim. Todavia, mais que um passo para a saúde os estados doentios constituem-se num movimento da saúde mesma. Para que isso ocorra é necessário que a doença não vire ressentimento. Quanto ao ressentimento, este, captura um estado de doença e a possibilidade de dor-reflexão-movimento fica inerte. A experiência com as afecções da alma, tristezas, ansiedades, depressões, etc., são vetores e nos levam a dois tipos distintos de seguimentos de vida.

De um lado, tomar um acontecimento como fato negativo, ou mesmo doentio, parte daquilo que aprendemos. Saúde ou doença se tornam um fardo quando nomeadas por diagnósticos. Nesse sentido, o ser humano passa a carregar uma carga desde sua aceitação de um diagnóstico. Para lidar com muitas sensações somos orientados, educados a barrar os processos de sofrimento. Uma dessas formas é o uso da medicação que pode começar a partir de um problema específico, aplacar as sensações de desconforto, mas nunca ter seu fim, ou seja, ser usado por toda vida. Percebemos, também, uma relação de quem manda e quem obedece no que concerne ao diagnóstico. Geralmente, neste sentido, os profissionais - médicos, psiquiatras, psicólogos, enfermeiros e até educadores - são os agentes ativos que prenunciam, autorizados pelos seus anos de estudos, aquilo que os pacientes/alunos serão. 
Criar Educação, Criciúma, v. 9, oㅡ 3, ago/dez. 2020 - PPGE - UNESC - ISSN 2317-2452

\section{Pistas}

\section{Pista 1: o churrasco}

Em 2013 comecei, pela primeira vez depois de formado em psicologia a trabalhar em uma instituição de saúde. Neste caso, era parte da equipe de um Centro de Atenção Psicossocial Álcool e Drogas (CAPS AD) em um pequeno município do interior do Rio Grande do Sul.

Como psicólogo era encarregado de algumas funções entre as quais destaco: psicoterapia individual ou em grupo e redigir pareceres e avaliações de encaminhamento para instituições de recuperação. Outras práticas tais como entrevistas de acolhimento, visitas domiciliares (VD), reuniões de equipe e com a administração municipal, contatos com a rede de saúde, assistência social, educação e justiça podiam ser realizadas por toda equipe.

Os acolhimentos eram práticas de recepção a cargo de um ou mais membros da equipe de saúde. Prestar atenção no paciente e realizar uma primeira entrevista era parte determinante das atividades que exercíamos. Pessoalmente desenvolvi o hábito de iniciar o acolhimento apresentando o ambiente institucional para os pacientes como quando se recebe uma visita em casa.

Estávamos ainda sob o efeito da campanha Crack, Nem Pensar (2011) realizada pelo grupo RBS. O clima criado pela campanha nos envolvia a todos: profissionais da saúde e usuários. Era comum associar usuários de crack a um estereótipo de zumbi e pensar que o crack causa dependência no primeiro uso. A sociedade foi tomada por uma maciça campanha com informações em rádio, TV, jornais impressos, outdoors, novela e eventos, todos mostrando o uso do crack como uma espécie de viagem sem volta e o usuário da droga como o epicentro (vítima e causador) da maior mazela social imaginável: o comprometimento da juventude passível de um encontro com a substância.

A partir do trabalho de acolhimento era possível perceber que a maioria daqueles que acessavam o CAPS, apresentavam boa organização em seu jeito de viver, inclusive em seu uso de crack. Não roubavam ou usavam objetos de parentes como 'moeda de troca'. Chegavam com boa saúde física e mental, agilidade de 
raciocínio de resposta e facilidade de integração no grupo. O principal motivo de estarem ali era devido à pressão familiar por terem descoberto que um de seus membros era usuário de droga. Havia casos de pessoas que chegavam com comprometimento de saúde física e mental devido ao uso do crack, mas eram muito poucos.

Foi possível observar que após um curto período de convivência no CAPS, mais ou menos uns quinze dias, havia uma grande mudança nos novos ingressantes. Passavam a mostrarem-se taciturnos, frágeis, deprimidos, em uma desgastante luta interna sobre a continuidade do uso ou não. Essa luta interna era alimentada, em grande parte, pelo mito da recaída. A recaída tinha como norte a crença de que qualquer uso, mesmo fortuito, após o propósito de deixar de usar qualquer substância ilegal, anulava todo esforço já feito e implicava em recomeçar do zero todo o processo. Ou seja, impedia a compreensão e a valorização do processo como um todo. $\mathrm{Na}$ medida em que o usuário ia se convencendo de que era doente.

Quando já estava por se completar um ano de trabalho no CAPS e já com um relativo conhecimento das dinâmicas da rede, da equipe e dos usuários resolvi promover um churrasco com a participação de todos: foram convidados integrantes da rede pública que davam suporte às atividades do CAPS, os colegas da equipe de trabalho, usuários de drogas sem vínculo com o CAPS, inclusive ex-usuários e familiares. Entre outras finalidades, esta promoção buscava integrar pacientes antigos do CAPS que não frequentavam mais a instituição, mas que sabíamos que estavam em uso excessivo de álcool. Alguns pacientes internados em situação de recuperação também receberam convite e com o consentimento das instituições responsáveis por seu tratamento também participaram.

$\mathrm{Na}$ ocasião da proposta de promovermos uma confraternização, tínhamos em mente oferecer ao grupo uma oportunidade de encontro. No entanto, em meio à empolgação com a notícia os pacientes do CAPS começaram a manifestar em que gostariam de ajudar. Assim, um disponibilizou-se a ser o assador, outro a ser seu ajudante, outros a ajudar na limpeza e organização do ambiente, receber os mantimentos enviados pela prefeitura e prepará-los, etc. Neste ponto, pude perceber que aquilo que seria um oferecimento organizado pela equipe do CAPS passou a 


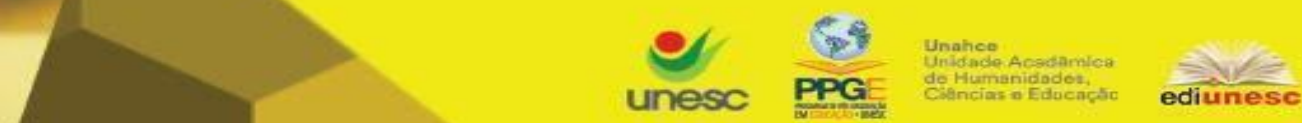

Criar Educação, Criciúma, v. 9, nº 3, ago/dez. 2020 - PPGE - UNESC - ISSN 2317-2452

mostrar uma qualidade de ativação dos usuários no sentido de sentirem-se responsáveis pela efetivação daquele encontro. A partir daí, percebendo a empolgação e a disponibilidade alegre dos usuários comecei a dar lugar, abrir espaço para os impulsos de cooperação que eles apresentaram. Desse modo, o jovem que era conhecido na região por realizar furto no supermercado acompanhou outro usuário para comprar itens que faltaram. Poder entrar num supermercado como comprador e não de maneira fortuita, disfarçada para subtrair coisas, abriu espaço para uma nova disposição na abordagem clínica do seu caso e na problematização do papel do roubo nas dificuldades que estava encontrando. A partir daí ele pode olhar para a imagem de ladrãozinho que produziu na cidade e desafiá-la de modo bastante positivo.

Nessa mesma linha foi possível observar uma atualização das potências de convivência em grupo e de cooperação observada, claramente, naqueles que se dispuseram em limpar e organizar o ambiente, marcados, até então por serem desleixados e tomados como incapazes. A chegada dos ex-pacientes alcoólatras foi marcante. Conhecidos na cidade por seu isolamento e, total dependência dos seus familiares apareceu bem dispostos com a melhor roupa honrado o convite.

O encontro transcorreu num clima de festa plena tanto pela qualidade da organização que envolveu numa horizontalidade nunca antes vista dos usuários e da equipe técnica do CAPS, quanto pelas conversas que envolviam futebol, política local, contação de causos e vivências envolvendo situações únicas decorrentes do uso de drogas que ali apareciam de modo leve, divertido e integrador.

Sem que percebêssemos, temas como recaídas, situações vergonhosas, perdas, auto percepções negativas, de difícil abordagem em uma clínica tradicional, começaram a circular no grupo e acompanhados da percepção e de comentários dos participantes que se reconheciam como estando "no mesmo barco" geraram um clima de confiança, de abertura e de troca. Enfim, havia, ali, evidentemente, uma clínica em movimento.

Ao final, contudo organizado e limpo, nos despedimos alegremente. 


\section{$\rightarrow$ है है \\ unesc PPG

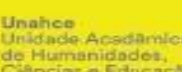 \\ ediunesc}

Criar Educação, Criciúma, v. 9, nº 3, ago/dez. 2020 - PPGE - UNESC - ISSN 2317-2452

\section{Pista 2: dançar}

Em uma manhã de verão, na qual estávamos em três funcionários na sala de entrada do CAPS realizando tarefas cotidianas, entra um jovem - que aqui vou chamar de Salvador - dos seus vinte e dois anos, negro, bem vestido, correntes e pulseiras, ar grave, preocupado, dirige-se a mim pedindo internação. Como de praxe, busquei o prontuário e dei uma olhada rápida. A leitura do prontuário permitiu saber que ele já havia passado por três internações e tomava medicação para "tratar" seu problema com o uso de crack. Em seguida, fui ver a parte do prontuário que sempre me chamava à atenção, pois era a resposta do paciente à pergunta "O que você gosta de fazer?". No prontuário de Salvador, a resposta era apenas uma palavra: dançar. Até hoje não sei exatamente quem fez as questões do prontuário de institucionalização, tampouco aquela pergunta, a mais interessante para mim. No entanto, a resposta de Salvador para aquela questão fez uma diferença incrível.

Com isso, deixei o prontuário e me dirigi a Salvador dizendo que havia lido sobre seu interesse na dança e perguntei, diretamente, se gostaria de fazer algumas oficinas de dança ali no CAPS com os outros pacientes. Olhou-me, muito espantado, e respondeu decididamente que não. E explicou: o tratamento para o uso de drogas era medicação e internação, e era isso que foi buscar ali. A partir dessa resposta, respeitei e procedi aos protocolos para encaminhar seu pedido: consulta médica e solicitação de vaga num hospital especializado da região centro do Estado. Salvador conseguiu a internação, mais ou menos, duas semanas depois. Nesse tempo de espera, não usou crack.

Oito meses depois, encontro Salvador que havia retornado ao CAPS para uma consulta com o psiquiatra. Parecia bem, vestia um boné, roupas largas, brinco, pulseira, sorria. A me ver, veio, com ar tranquilo, em minha direção e perguntou se a proposta da oficina de dança estava de pé. Desta vez, o espanto foi meu. Espanto que logo se misturou a um contentamento e a resposta afirmativa: claro!

Decidimos, então, realizar, no CAPS, um espaço para a dança, em que, pela primeira vez, um paciente ministraria a oficina. Era preciso saber como Salvador dançava, de certa forma eu já pensava mais adiante em levar a oficina para outro público. 
Reunimo-nos, assim, em uma sala de atendimento individual para a primeira aula/oficina. Estávamos entre seis pessoas: alguns pacientes, a mãe de Salvador (contente em ver seu filho responsável por uma oficina no CAPS) e membros da equipe. Foi então que Salvador começou a dançar embalado pelos ritmos do Funk e do Hip-hop. Sua alegria era visível.

Após duas sessões realizadas no CAPS - que não foram marcadas pelo ânimo dos participantes, mas pelo empenho de Salvador e suas qualidades como dançarino - tivemos, então, a ideia de levar a oficina para alunos de escolas. A partir desse encontro constituímos uma equipe formada por Salvador, eu, outro paciente do CAPS que gostava de dançar, o nosso motorista e outro paciente com problemas de mobilidade em uma perna que se encantou pelo trabalho. O transporte da equipe era garantido por um dos usuários com histórico de alcoolismo que se dispôs a nos levar, e aos equipamentos, sempre que necessário. Todas as vezes que compareceu para realizar o que se havia disposto a fazer, estava sóbrio, bem arrumado e dirigia com muito cuidado. O paciente com problemas de mobilidade não dançava. Todavia, fazia um importante trabalho de intermediar as instruções de Salvador, muitas vezes não compreendidas pelos alunos de dança, traduzindo-as de modo simples e compreensível. Decidimos, conjuntamente, como ponto de partida duas escolas da cidade. Começamos nossa caminhada até a primeira instituição de ensino. Junto com dois frequentadores, entre sonhos (imaginávamos dando a oficina de dança), medos (não sabíamos como seríamos recebidos na escola) e risos (entre decidir o melhor caminho para chegar à escola e contar histórias que nos ocorriam, riamos muito).

Fomos muito bem recebidos pela escola o que nos animou a oferecer também o trabalho para outra escola. Em pouco tempo, tínhamos duas oficinas acontecendo: uma, numa escola do município, e a outra no centro da cidade. Salvador não tinha uma experiência pedagógica, mas tinha uma vontade enorme em desenvolver as oficinas de dança. Frequentemente, ligava-me à noite para explicar como seria a aula da semana. Além disso, resolvemos nos encontrar no CAPS antes e depois das oficinas, pois ali definíamos como seriam as aulas, mesmo que o tempo tenha nos mostrado que uma aula/oficina se transformava o tempo todo enquanto acontecia. Levar algo pronto, ao início da oficina, devia ser uma orientação para o trabalho com 
Criar Educação, Criciúma, v. 9, № 3, ago/dez. 2020 - PPGE - UNESC - ISSN 2317-2452

as turmas e não um tipo de "receita" da atividade. Tratava-se de uma orientação que precisava o tempo todo estar aberta a redirecionamentos e novas estratégias.

Em meio a toda essa reflexão, em uma determinada ocasião, Salvador e eu encontramos alguns alunos da oficina caminhando na rua. Os alunos estavam fora da escola tendo em vista a não realização da aula de Educação Física (segundo o que contaram o professor havia faltado). Em meio a esse encontro, um dos meninos veio até Salvador e perguntou sobre alguns passos de dança que haviam desenvolvido anteriormente. Contagiado pela vontade de aprender o passo, o menino também provocou o interesse nos demais. Assim, um simples encontro propiciou a realização de uma oficina.

Sem lugar e hora combinados, sem hierarquia, todos iniciaram movimentos coreográficos na rua. Movidos por um desejo coletivo de aprender, estabeleceu-se um processo educacional.

O trabalho de Salvador, com suas oficinas junto ao CAPS estendeu-se por um ano e meio, atendendo a públicos tão diversos quanto os já mencionados integrantes do CAPS, as crianças e jovens nas escolas, grupo de terceira idade e a participação em diversos eventos da cidade.

\section{Pista 3: escrever}

Eu ia pela calçada, em direção ao mercadinho perto de casa, quando um jovem se aproximou dizendo: oi! Lembra de mim?. Eu não lembrava, mas ele logo acrescentou que havia assistido uma fala minha na URI de Santiago. Entre outras coisas que conversamos manifestou em escrever um artigo sobre saúde e doença na perspectiva Nietzscheana.

Disse que se ele quisesse alguma ajuda que poderia aparecer na minha casa (e, com isso, nos despedimos) desde que levasse algo escrito sobre o que gostaria de desenvolver.

Dias depois ele aparece em casa. Trazia um pequeno caderno e nele duas frases. A leitura não foi muito animadora, mas perguntei: o que você quis dizer com essa frase que li em voz alta. Ele passou a contar que desejava escrever sobre os 
Criar Educação, Criciúma, v. 9, № 3, ago/dez. 2020 - PPGE - UNESC - ISSN 2317-2452

problemas que a noção de saúde vigente produzia, teve essa ideia a partir de um breve estágio acadêmico que realizará junto a um CAPS. A marcante divisão de separação entre os pacientes e a equipe de trabalho e a sua preferência por estar junto aos pacientes, no pátio, em meio a conversas e jogos indicou-lhe que havia mais saúde a convivência deles do que na da equipe que se mantinha, a maior parte do tempo confinada em algumas, poucas, dependências do CAPS. Este foi o ponto de partida, a questão, o problema em torno do qual se daria a pesquisa para o seu artigo. Certo, disse eu, vamos escrever isso aí que você acabou de falar. À medida que íamos relembrando o que ele havia dito ele ia escrevendo frase por frase. Experimentávamos, lentamente a operação de passar da linguagem oral para a escrita. Depois, relemos, ajustamos alguns pontos e percebemos que já havia ali uma ideia escrita.

Com mais ou menos dois parágrafos, encerramos aquela sessão e antes de nos despedirmos ele disse com desânimo que não daria conta de fazer um artigo, pois, não sabia escrever. Referindo-se ao grau de elaboração exigido na escrita acadêmica. Nesse ponto eu disse: sim, mas só há um jeito, para escrever bem, só se consegue escrevendo. Indiquei que prestasse atenção no conceito de normal, na noção de saúde, e também textos: Lima Barreto, Sandra Capini e Georges Canguilhem. Pedi, então que voltasse com algumas impressões de leituras escritas. Em menos de três meses tinha seu artigo pronto.

Conversamos sobre a possibilidade de apresentar seu artigo em um evento. Inscreveu-se no congresso da Associação Brasileira de Psicologia Social (ABRAPSO) de 2009, que se realizaria em Maceió e obteve aprovação. Daí foi toda uma história de reunir as condições para o pagamento da inscrição, passagens e estadia que, com dificuldade conseguiu junto a seus familiares.

Com tudo arranjado e já às vésperas da viagem veio até mim dizendo que havia desistido da viagem. Perguntado sobre o motivo falou, entre outras coisas, que seria a primeira vez que falaria em um evento, viajaria de avião, que iria tão longe. Perguntei, então, o que estava sentido. Ele disse: medo. Perguntei se o medo estava ali com ele naquele momento. Sim, disse. Foi então que Ihe perguntei: não seria 


\section{P $>$ है है \\ unesc PPGE

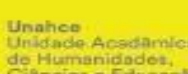 ediunesc}

Criar Educação, Criciúma, v. 9, nº 3, ago/dez. 2020 - PPGE - UNESC - ISSN 2317-2452

interessante levar o teu medo para viajar de avião, conhecer Maceió e as pessoas de lá? Aproveita isso, vocês podem se divertir.

Quanto ao medo de apresentar o trabalho lembrei que ele tinha um bom trabalho que deveria se concentrar em apresentar aquelas ideias para as pessoas e ficar atento se elas Ihe dessem algum retorno. Com sugestões, criticas que contribuíssem para o trabalho. A timidez a gente ultrapassa tendo o que dizer. E tu tens.

Dias depois retornou para contar sobre a viagem, sobre Maceió e sobre os efeitos da apresentação de seu trabalho e de como foi bem recebido pelo público, o que ficou claro pelas diversas pessoas que o abordaram no evento fazendo perguntas e comentando suas ideias, e pedindo referências dos autores.

A partir desse encontro tivemos muitas oportunidades de trabalhar junto, de discutir situações, de enfrentar dificuldades e comemorar êxitos. E hoje estamos aqui escrevendo juntos este texto.

\section{Uma clínica dos encontros}

O churrasco foi oportunidade para a emergência de um impulso de participação e de cooperação que só ali poderia ter lugar. Tornou-se um campo de ação em que se experimentaram trocas múltiplas entre os participantes: histórias de vida, conversas abertas sobre o uso de drogas e a relação delas com vários âmbitos da vida de cada um. O uso de drogas tornou-se argumento das conversas gerando chistes, brincadeiras e a troca de vários modos de viver experiências tomadas, a princípio, como uniformes e, em seguida, foi bonito ver surgir uma nova perspectiva sobre o próprio uso de drogas na medida em que as experimentações sobre o uso eram partilhadas amigavelmente e sem juízos morais. A atenção de que essas manifestações eram alvo, resultava em devoluções cujo efeito era adicionar elementos novos ao modo como cada um era percebido pelo grupo. Não mais apenas como usuário de álcool, crack ou maconha, esses rótulos passaram a coexistir com outros atributos. A partir do churrasco passamos a ter, no grupo, o contador de histórias, o motorista, o confidente, o pedreiro, o conhecedor da lida do campo e 
Criar Educação, Criciúma, v. 9, № 3, ago/dez. 2020 - PPGE - UNESC - ISSN 2317-2452

depois o dançarino, o poeta, o radialista, a organizadora ninja de espaços, a cuidadora atenta, o concerta tudo.

A negativa inicial de Salvador frente ao convite para oferecer uma oficina de dança afirmando que o que fora buscar no CAPS era a efetivação dos protocolos para sua internação nos mostra o quanto trabalhadores da saúde e seus acessados partilham de uma mesma perspectiva em relação às noções de saúde e doença. Entendemos que seu motivo estava de um modo muito forte atrelado à mecânica reinante nas ações de saúde dos CAPS AD ao fortalecer a linha doente-diagnósticotratamento-abstinência e à aura de pavor resultante das verdades violentas enfatizadas pela campanha Crack, nem pensar: você vicia na primeira dose. Todavia, quando criamos condições para as oficinas abriu-se um imenso campo de atuação envolvendo desejos, trabalho, competência, diversão e os sorrisos das crianças.

$O$ investimento em situações que reforçavam o enriquecimento dos atributos de cada um gerou uma abordagem clínica não mais movimentada pelas dualidades terapeuta-paciente, funcionário-usuário do serviço de saúde, sãos-doentes.

O fato de o CAPS se estruturar em torno da figura do usuário de drogas não pode ser negado nem negligenciado, todavia, inaugurou-se, ali, modos de convivência entre pessoas não caracterizadas mais por rótulos planos e redutivistas, fosse o de drogados, fosse o de membro da equipe técnica. Os encontros passaram a se dar com múltiplas linhas de interesse ligando uns aos outros.

Assim, deixou de ter destaque absoluto a linha doente-diagnóstico-tratamentoabstinência. Passam a ter lugar atividades e encontros voltados à consecução de projetos definidos em comum e, nisso tudo, novas perspectivas, dimensionamentos e intensidades em relação ao uso de drogas.

O encontro que inaugurou a associação dos autores do presente artigo moveu de modo simples um dos maiores mitos da formação acadêmica atual: os estudantes de hoje não sabem escrever. A escrita acadêmica tem sido objeto de muita preocupação. Em torno dela a universidade e os cursos de formação inicial e pósgraduação produziram uma série de dispositivos voltados a produção do item que assume o status de moeda corrente na produção científica: o artigo publicado em revistas indexadas. Tais dispositivos tomam corpo nas diversas disciplinas 
denominadas como introdução à pesquisa, metodologia da pesquisa e escrita acadêmica presentes em praticamente todos os cursos universitários. Tais disciplinas costumam reduzir-se a uma liturgia ou a uma série de ordenações do que é necessário fazer para a realização de um trabalho acadêmico. Nelas desfilam, com total desinibição, tipificações de metodologias, taxionomias de objetivos e opera com autoridade inquestionável a polícia do cumprimento das regras da ABNT. Pouco se vê, nessas disciplinas voltadas para facilitar a produção acadêmica a discussão sobre o que move o pesquisador a propor uma pesquisa. E uma pesquisa tem como centro pulsante uma questão viva a ser problematizada. Experimentamos as intensidades ligadas a um problema de investigação e suas consequências: vontade de estudar, interesse pelo que já foi escrito sobre um problema, e a alegria de encontrar e coproduzir um conceito tomado como ferramenta do pensamento.

No nosso encontro pudemos partir de uma situação de precariedade de condições para a escrita de um artigo para a realização do mesmo, com eficiência e reconhecimento da comunidade acadêmica, em poucos meses.

\section{Considerações Finais}

Eis aí o que pensamos serem pistas para uma clínica da diferença, do cultivo da capacidade de diferir que tanto nos incentiva (DELEUZE, 1997) não há nenhuma indicação possível de procedimento ou de garantia para sua emergência, ela envolve, todavia, um relaxamento dos papeis institucionais e dos atributos a eles ligados na direção de uma horizontalidade de relações. Tal horizontalidade é indício de que as pessoas envolvidas têm questões, ou problemas em comum. E são essas questões os ativadores das diferenças e os atualizadores das potências de apoio mútuo e alegria nos encontros.

A possibilidade de diferir é a aposta de tal clínica, pois é diferindo que somos capazes de produzir encontros alegres. Encontros nos quais podemos estar no exercício pleno de nossa presença. Ou seja, sem gastar toda energia na manutenção das figuras precárias e cansativas com as quais costumamos nos apresentar para a vida em ambientes sociais. 
Criar Educação, Criciúma, v. 9, oㅜ 3, ago/dez. 2020 - PPGE - UNESC - ISSN 2317-2452

A manutenção de uma figura de identidade seja ela negativa (usuário de drogas) ou positiva (psicólogo, médico, professor, funcionário) exige toda sorte de investimentos, afetivos e psicológicos, toda uma gama de posturas corporais e faciais adequadas, todo um repertório de palavras e frases... Elas exigem todo um cálculo para o controle de emoções, gestos e expressões. Em meio a tanto que fazer, é comum que percamos nossas qualidades de presença, nossa escuta, nossa atenção ao que acontece.

Quando as figuras que indicam as funções que exercemos deixam de reinar absolutas nas relações com os outros, temos multiplicadas as vias de circulação dos afetos. Ampliam-se nossas capacidades de afetar e de sermos afetados, bem como a intensidade daquilo que acontece, intensifica-se o viver a vida.

\section{Referências}

BERLINGUER, G. Psiquiatria e poder. Tradução de Otho Faria. 3‥ Ed. Belo Horizonte: Riuniti, 1969.

CAPONI, S. Da Compaixão à Solidariedade: Uma Genealogia da Assistência Médica. Rio de Janeiro: Fiocruz, 2004.

DELEUZE, G. Crítica e clínica. Tradução de Peter Pal Pélbart. São Paulo: Editora 34, 1997.

FUGANTI, L. Saúde, desejo e pensamento. São Paulo, Hucitec, 2008.

GIACOIA, O. Nietzsche: o humano como memória e como promessa. Petrópolis: Vozes, 2013.

HARI, J. Na Fissura: uma história do fracasso no combate às drogas, Tradução: Hermano Freitas. Companhia das Letras: São Paulo, 2015.

ILLICH, I. A expropriação da saúde: nêmesis da medicina. Tradução de José Kosinski de Cavalcanti. 3. ed. Rio de Janeiro: Nova Fronteira, 1975.

MERHY, E. Anormais do desejo: os novos não humanos? Os sinais que vêm da vida cotidiana e da rua. In: Drogas e Cidadania: em debate/Conselho Federal de Psicologia. - Brasília: CFP, p. 09-18, 2012.

NIETZSCHE, F. Genealogia da Moral (tradução de Paulo César de Souza). São Paulo: Companhia das Letras, 1999 

das Letras, 2001.

A gaia ciência. Trad. Paulo Cesar de Souza. São Paulo: Companha Crepúsculo dos Ídolos. Trad: Paulo César de Souza. São Paulo:

Cia das Letras, 2006

OLIVEIRA, L. K. Clínica Saúde e Educação: Estratégias de cuidado com usuários de Drogra. Dissertação (Mestrado em Educação), Universidade Federal de Santa Maria, Santa Maria, RS, 2017.

Recebido julho de 2020

Aprovado setembro de 2020 